\title{
Regulation of gene expression in tissue engineering, differentiation and bone regeneration of ossifying stem cells Amirhosein Nezakat Yazdi $^{1}$, Nastaran Sahraei ${ }^{1}$, Mehdi Ahmadifar ${ }^{12^{*}}$
}

1. Department of biology, college of science, University of science and culture, ACECR, Tehran branch, Iran

2. Department of Stem Cells and Developmental Biology, Cell Science Research Center, Royan Institute for Stem Cell Biology and Technology, ACECR, Tehran, Iran

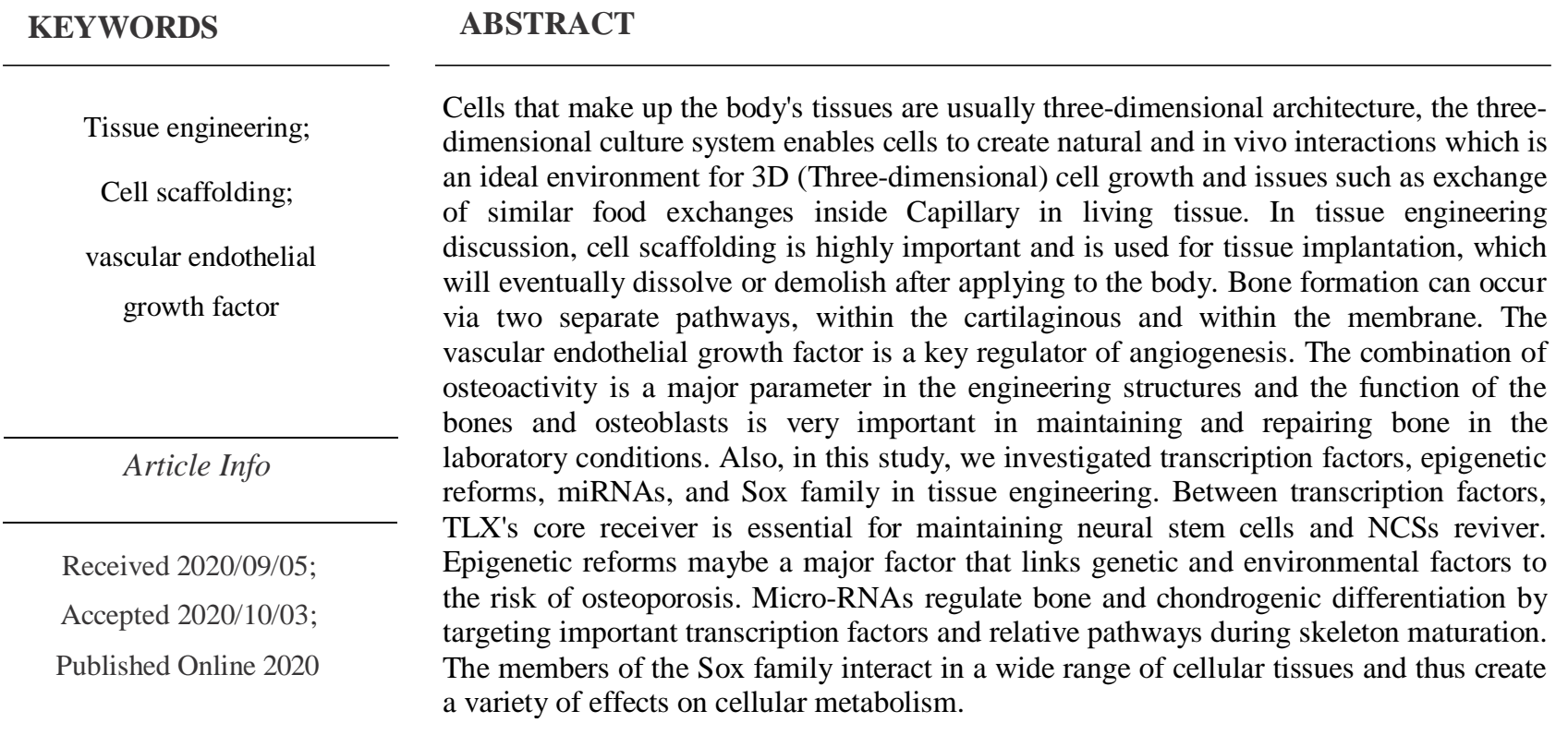

Corresponding Information: Mehdi Ahmadifar, Department of Stem Cells and Developmental Biology, Cell Science Research Center, Royan Institute for Stem Cell Biology and Technology, ACECR, Tehran, Iran, E-mail:

Mehdi_ahmadifar67@yahoo.com

Copyright $\odot$ 2020. This is an open-access article distributed under the terms of the Creative Commons Attribution-noncommercial 4.0 International License which permits copy and redistribute the material just in noncommercial usages, provided the original work is properly cited.

\section{Abbreviations}

RPT, Periodontal Regeneration Technique; 2D, Two-Dimensional; 3D, Three-Dimensional; ECM, Extracellular Matrix; VEGF, Vascular Endothelial Growth Factor; HiF-1, Hypoxia-Induced Reversal; EPC, Endothelial Progenitor Cell; HDPSCs, Human Dental Pulp Stem Cells; SGZ, Subgranular Zone; GD, Gadolinium; SVZ, Subventricular Zone; REST, transcription factor RE1; PRmiRNAs, Primary miRNAs; EEmiRCs, Primary Embryonic miRNAs; SRy, Sex-Determining Region Y.

\section{Introduction}

Tissue engineering is used to create bio-alternatives that can restore, preserve, and improve the function of damaged tissues. The main components in scaffold tissue engineering are cells and growth factors (1). The scaffold is a three-dimensional structure that is used as a framework to guide cells and is an alternative to the extracellular matrix. The cells penetrate the scaffold and begin to grow, differentiate, proliferate and migrate according to the physical and chemical signals around them, and if the environmental conditions are favorable, they secrete an extracellular matrix and create the new tissue (2) (Fig. 1). Nanotechnology is the engineering of functional systems that covers a wide range of topics at the molecular level and focuses on controlling and exploiting the structure of matter at a scale below 100 nanometers. 
36 Regulation of gene expression in tissue engineering...

In recent years, the use of many nanomaterials, including nanocapsules, nanoparticles, and nanofibers with a size of less than $100 \mathrm{~nm}$ has attracted the attention of researchers in the diagnosis and treatment of diseases (3).

\section{Bone tissue engineering}

Biomaterials used in the manufacture of porous scaffolds include natural and synthetic compounds. Biomaterials are obtained from natural sources (plant or animal); collagen, chitosan, agarose, alginate, and fibrins are natural materials discovered for RPT ${ }^{1}$. Chitosans can be the best choice when scaffolds are exposed to a transparent environment because they have antibacterial activity against the risk of bacterial contamination.

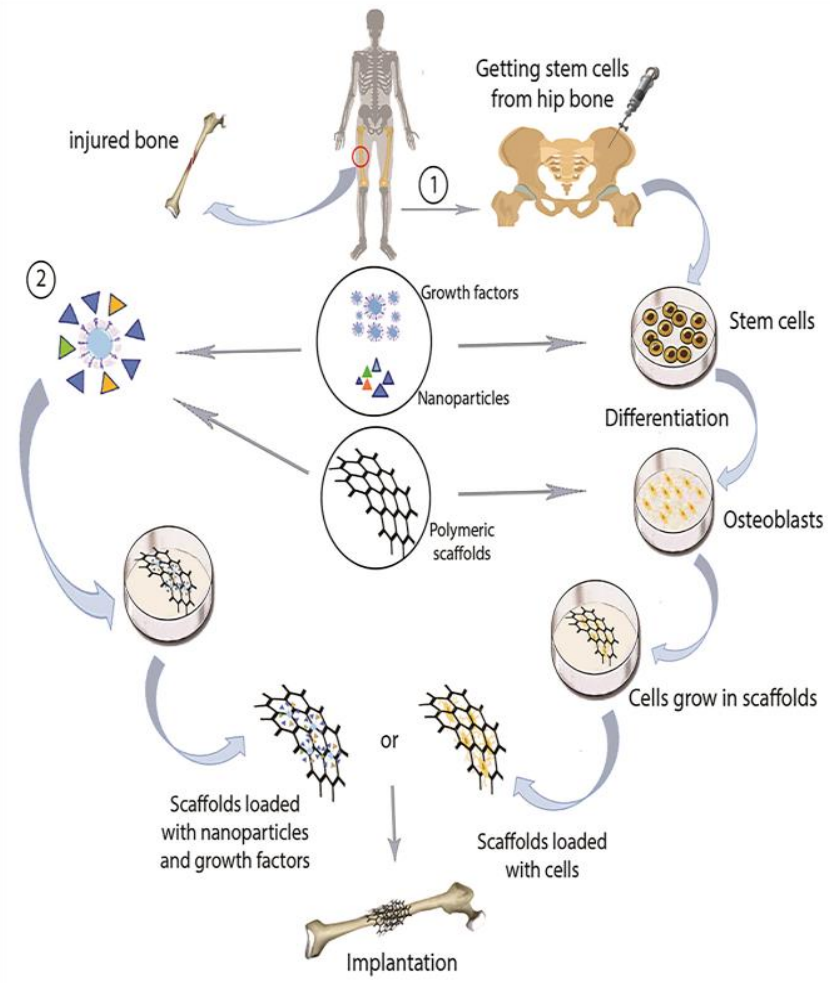

Figure 1. Growth factors and nanoparticles can repair bone in two ways.

1) They differentiate stem cells from osteoblasts.

2) Both directly cause cells to grow and differentiate.

\section{Cell scaffolding and stimuli for in vitro modeling}

Experiments performed on $2 \mathrm{D}^{2}$ cell culture systems have resulted in extensive knowledge in the early life sciences (1); However, the morphology of cells growing in 2D media is significantly different from those of cells in real tissues, because 2D media is usually flat and cells grow only in $\mathrm{x}$ and $\mathrm{y}$ directions. It is endangered as a result of the interaction of one cell with another and also, this harms gene expression, protein synthesis, and other cellular functions $(3,2)$.

The cells that make up the body's tissues usually have a three-dimensional architecture, and for this reason, three-dimensional cell culture and related tools have been developed in recent decades. The range of the vertical axis of the third dimension is between a few micrometers to centimeters and supports cells for complex three-dimensional interactions with adjacent cells and produce more layers $(4,5)$. Also, a threedimensional culture system; empowers cells to create intercellularly and in vivo interactions, providing an ideal environment for the growth of $3 \mathrm{D}^{3}$ cells, and issues such as nutrient exchange similar to capillary exchange in living tissues $(1,3,6)$.

\section{Classification of cell scaffolds:}

1) $3 \mathrm{D}$ cell culture scaffold, which is mainly used in renewable medicine or cell behavior studies.

2) 3D tissue engineering scaffolding which is used for tissue growth and reproduction $(9,8,7)$.

The main difference is based on whether the scaffolding dissolves after use or not. 3D cell scaffolding is used in the laboratory for cells culture, study, or analysis and is not dissolved or destroyed after usage $(8,7,6)$. Tissue engineering scaffolding is used for tissue implantation and tends to dissolve or destroy after application to the body. The porosity of the scaffold varies from nano to micro-level, the number of pores per square centimeter is significantly different and is generally from approximately 50 to $600(12,11,10)$. Two types of isotropic and orthotropic architectures are mainly used on three-dimensional scaffolds. Both offers specific stimuli on cells as well as different mechanisms in scaffold structures $(14,13,8)$. Scaffolding mechanics are important because they help tissues and cells maintain their integrity and proper function $(13,8,2)$. The mechanical properties of scaffolding can be mainly affected by the size, dimensions, and materials used in construction. Studies show that physiological processes can affect the mechanical properties of cell environments. These mechanical properties can cause vulnerabilities and cellular behaviors to differentiate and increase growth and etc. The mechanical properties of 3D scaffolding are generally dependent on the texture and its hardness is from $0.3-1 \mathrm{kPa}$ to an average hardness of 8-17 kPa and above. Therefore, adjusting the mechanical properties for 3D scaffolding design helps to ensure physiological rigidity and mechanical supports; This can help in better cell uptake as usual as well as the remaining intermittent mechanism in dynamic cells vibration $(16,15,2)$.

Scaffolds and their products must be compatible in all respects. This requires that, the scaffold material be non- 
toxic to cells, easily removed from the body, and have a low immune response due to its presence. If a scaffold is not destroyed quickly enough, the inflammatory response can lead to external scaffold material and impair tissue regeneration (17).

Macroscopically, bones are made up of interconnected trabecular tissues, each with very different mechanical strength and stiffness (18). At the molecular level, the $\mathrm{ECM}^{4}$ is composed mainly of fibrous macromolecules, glycosaminoglycans, and glycoproteins[.] (19).The bone is first supplied with blood by an arterial network. Inside the brain cavity; The bones and canals of the Haversian carry blood vessels to thin-walled capillaries whose main role is to exchange nutrients and signals between blood cells (20).

Bone formation can occur through two distinct pathways, intra-cartilage and intra-membrane. In each case, the first step is to compress the mesenchymal cells to create a pattern for subsequent bone formation (21). Intracartilage ossification; The direct differentiation of mesenchymal progenitor cells into osteoblasts and intramembrane ossification; Differentiation of mesenchymal progenitor cells into chondrocytes and subsequent hypertrophy is matrix mineralization and replacement with bone tissue. Both pathways of bone formation occur near arteries (22). During intramembranous bone formation, mesenchymal tissue is affected, while in intracartilaginous bone formation, overactive cartilage cells cause blood vessels to absorb and penetrate (23). Primary arteries are associated with invasion of osteoclasts and osteoblasts and, coordination, with overactive cartilage, ECM mineralization, and bone formation; Reabsorbed. VEGF $^{5}$ is a key regulator of angiogenesis and consequent bone development; VEGF-A levels also depend on hypoxia-induced reversal ${ }^{6}$, resulting in bone mass modulation (24). Creating a functional vessel within the structure can be necessary to create a broad and accurate model that can mimic its tissue. Current vascular strategies include; The use of angiogenic factors is combined with 3D scaffolding and the use of culture systems.

The first angiogenesis-based approach by endothelial precursors using angiogenic agents (angiogenic factors) such as VEGF. Studies show that the "electrospun poly (caprolactone)" scaffold with the VEGF layer causes the penetration and proliferation of EPCs ${ }^{7}$ in the $3 \mathrm{D}$ matrix. This process is regulated to endothelial cells and in the field of tissue engineering, special interactions with scaffolding and other cells types are required to optimize vascular formation in vitro (25) (Fig. 2). Osteocytes are

\footnotetext{
${ }^{4}$ extracellular matrix

${ }^{5}$ Vascular endothelial growth factor

${ }^{6} \mathrm{HiF}-1$

${ }^{7}$ Endothelial progenitor cells
}

distinctly stable osteoblasts located in cavities within the bones matrix. They travel through cells processes to the mineral matrix inside small canals called "canaliculi" that are filled with canalicular fluid (26). Although osteocytes play a secondary role in bone formation, they play an important role in homeostasis, mechanization, and transmission mechanics $(28,27)$. One of the parameters that must be considered when creating vascular bone in vitro is the combination of osteoclast activity within the engineered structures. Osteoclasts for bone regeneration by remodifying the bone matrix and creating physical space for osteoblasts and endothelial cells, new bone tissue with sufficient arteries can be formed. The dissolution of the mineral phase of the bone matrix is mediated by the secretion of hydrochloric acid and the absorption of the organic matrix by secreted enzymes such as cathepsin $\mathrm{K}$ and metalloproteinase9 (29).

The ideal in vitro model of bone should consider the possibility of studying its interaction with other tissues, thus creating considerable challenges in replacing different specific tissue environments. Stem cells are an exceptional tool for achieving this complex integration between bones and other tissues due to their multiple capabilities.

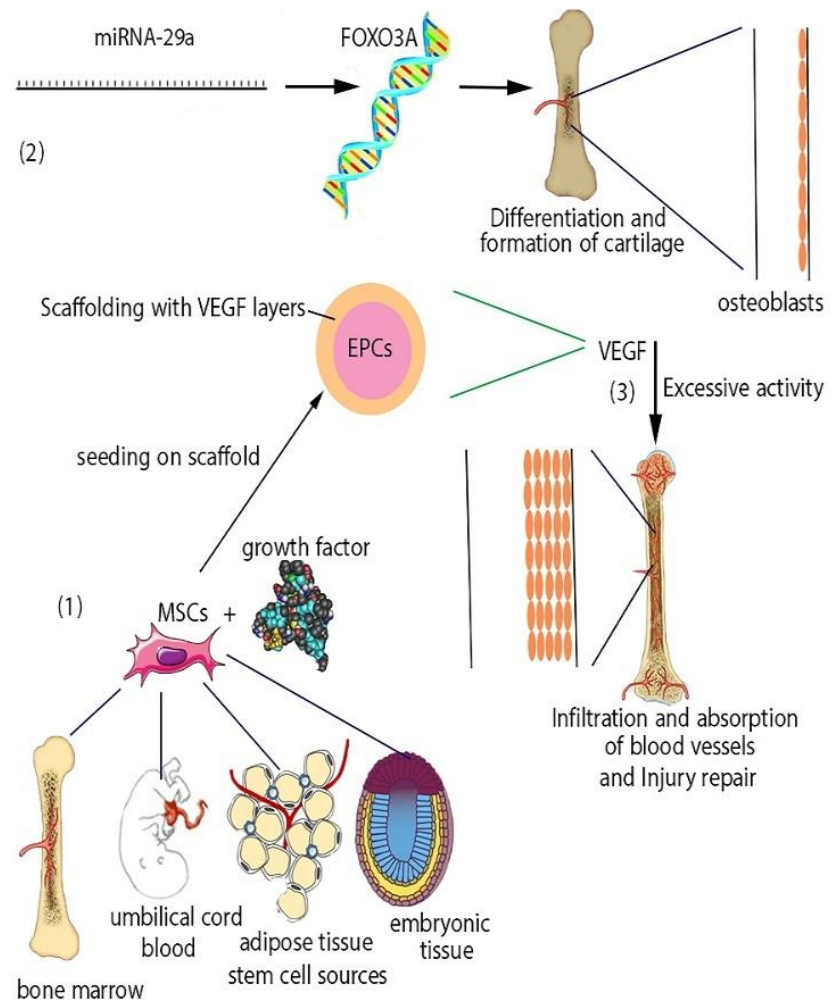

Figure 2. 1. Mesenchymal stem cells are extracted from bone marrow, umbilical cord blood, fat cells, or embryonic tissue and transferred to scaffolds along with growth factors. 2. In miRNA-29a cells, by targeting the foxo3a gene, it provides differentiation and formation of cartilage, which is due to the activity of cartilage due to theinfluence of angiogenic factors such as VEGF. Angiogenesis and repair of damaged tissue occur. 
38 Regulation of gene expression in tissue engineering...

Table 1. List of in vivo studies in which the potential HDPSCs ${ }^{l}$ for bone tissue engineering were examined and the experimental model, type of scaffold, bone defect were created and the time and method of identification of each of them were used.

\begin{tabular}{|c|c|c|c|c|c|}
\hline Author & $\begin{array}{l}\text { Experimental } \\
\text { model }\end{array}$ & Scaffold type & Defect & Evaluation method & $\begin{array}{l}\text { Evaluation } \\
\text { time }\end{array}$ \\
\hline Miura et al. ${ }^{17}$ & $\begin{array}{l}\text { Mice } \\
\text { Immunological }\end{array}$ & $\begin{array}{l}\text { HA/TCP } \\
\text { ceramic }\end{array}$ & $\begin{array}{l}\text { Skull defect } \\
\text { scaffolding }\end{array}$ & $\begin{array}{c}\text { Histology } \\
\text { Immunohistochemistry, } \\
\text { in local hybridization and } \\
\text { RT-PCR }\end{array}$ & 8 weeks \\
\hline $\begin{array}{l}\text { LAINO et } \\
\text { al.18 }\end{array}$ & $\begin{array}{l}\text { Mice } \\
\text { Immunological }\end{array}$ & $\begin{array}{c}\text { Bone } \\
\text { subcutaneous } \\
\text { tissue is made } \\
\text { by HDPSCs }\end{array}$ & Implant & Histology & 4 weeks \\
\hline $\begin{array}{l}\text { PAPACCIO } \\
\text { et al.19 }\end{array}$ & $\begin{array}{l}\text { Mice } \\
\text { Immunological }\end{array}$ & $\begin{array}{c}\text { Bone } \\
\text { subcutaneous } \\
\text { tissue is made } \\
\text { by HDPSCs }\end{array}$ & Implant & $\begin{array}{c}\text { Histology and } \\
\text { immunofluorescence }\end{array}$ & 4 weeks \\
\hline $\begin{array}{l}\text { et al.20 } \\
\text { LAINO }\end{array}$ & $\begin{array}{l}\text { Mice } \\
\text { Immunological }\end{array}$ & $\begin{array}{c}\text { Bone } \\
\text { subcutaneous } \\
\text { tissue is made } \\
\text { by HDPSCs }\end{array}$ & Implant & Histology & 4 weeks \\
\hline $\begin{array}{c}\text { GRAZIANO } \\
\text { et al.21 }\end{array}$ & $\begin{array}{l}\text { Mice } \\
\text { Immunological }\end{array}$ & $\begin{array}{l}\text { PLGA } \\
\text { membrane }\end{array}$ & $\begin{array}{l}\text { Subcutaneous } \\
\text { transplantation }\end{array}$ & $\begin{array}{l}\text { Histology, } \\
\text { immunohistochemistry } \\
\text { and immunofluorescence }\end{array}$ & $\begin{array}{l}\text { 30,40,60 } \\
\text { days }\end{array}$ \\
\hline $\begin{array}{l}\text { D'AQUINO } \\
\text { et al.22 }\end{array}$ & $\begin{array}{l}\text { Mice } \\
\text { Immunological }\end{array}$ & $\begin{array}{l}\text { Bones woven by } \\
\text { HDPSCs are } \\
\text { obtained } \\
\text { subcutaneously } \\
\text { in vitro }\end{array}$ & $\begin{array}{l}\text { PGA-TMC } \\
\text { implants and } \\
\text { scaffolding }\end{array}$ & $\begin{array}{c}\text { Histology and } \\
\text { immunohistochemistry }\end{array}$ & 4,6,8 weeks \\
\hline $\begin{array}{l}\text { OTAKI et } \\
\text { al. } 23\end{array}$ & $\begin{array}{l}\text { Mice } \\
\text { Immunological }\end{array}$ & $\begin{array}{l}\text { HA / TCP } \\
\text { powder }\end{array}$ & $\begin{array}{l}\text { Subcutaneous } \\
\text { transplantation }\end{array}$ & Histology & 7,15 weeks \\
\hline $\begin{array}{l}\text { GRAZIANO } \\
\text { et al.24 }\end{array}$ & $\begin{array}{l}\text { Mice } \\
\text { Immunological }\end{array}$ & $\begin{array}{l}\text { PLGA } \\
\text { membrane }\end{array}$ & $\begin{array}{l}\text { Subcutaneous } \\
\text { transplantation }\end{array}$ & $\begin{array}{l}\text { Immunohistochemical } \\
\text { histology, and } \\
\text { X-Ray diffraction }\end{array}$ & 4,8 weeks \\
\hline $\begin{array}{c}\text { DE } \\
\text { MENDONSA } \\
\text { COSTA et } \\
\text { al.25 }\end{array}$ & Rat & $\begin{array}{l}\text { Collagen } \\
\text { membrane }\end{array}$ & Skull defects & Histology & $\begin{array}{l}1,3,4,8 \\
\text { weeks }\end{array}$ \\
\hline ABE et al.26 & $\begin{array}{l}\text { Mice } \\
\text { Immunological }\end{array}$ & HA scaffolding & $\begin{array}{l}\text { Subcutaneous } \\
\text { transplantation }\end{array}$ & $\begin{array}{c}\text { Histology and } \\
\text { immunofluorescence }\end{array}$ & 12 weeks \\
\hline $\begin{array}{l}\text { ZHANG et } \\
\text { al.27 }\end{array}$ & $\begin{array}{l}\text { Mice } \\
\text { Immunological }\end{array}$ & $\begin{array}{l}\text { HA / TCP } \\
\text { ceramic } \\
\text { scaffolding }\end{array}$ & $\begin{array}{l}\text { Subcutaneous } \\
\text { transplantation }\end{array}$ & $\begin{array}{l}\text { Histology and real-time } \\
\text { PCR }\end{array}$ & 5,10 weeks \\
\hline $\begin{array}{c}\text { MORITO et } \\
\text { al.28 }\end{array}$ & $\begin{array}{l}\text { Mice } \\
\text { Immunological }\end{array}$ & $\begin{array}{l}\text { CAP / PLGA } \\
\text { scaffolding }\end{array}$ & $\begin{array}{l}\text { Subcutaneous } \\
\text { transplantation }\end{array}$ & Histology & 5,10 weeks \\
\hline $\begin{array}{l}\text { D'AQUINO } \\
\text { et al.29 }\end{array}$ & Human & Collagen sponge & $\begin{array}{l}\text { Third mill tooth } \\
\text { extraction defect }\end{array}$ & $\begin{array}{l}\text { Histology, X-ray, } \\
\text { immunofluorescence, and } \\
\text { Clinical evaluation }\end{array}$ & $\begin{array}{l}1,2,3 \\
\text { months }\end{array}$ \\
\hline $\begin{array}{l}\text { KRAFT et } \\
\text { al.30 }\end{array}$ & $\begin{array}{l}\text { Immunological } \\
\text { mice }\end{array}$ & $\begin{array}{l}\text { HA / TCP } \\
\text { granules }\end{array}$ & $\begin{array}{l}\text { Subcutaneous } \\
\text { transplantation }\end{array}$ & $\begin{array}{c}\text { Histology } \\
\text { Immunohistochemistry } \\
\text { and histomorphometry }\end{array}$ & 8 weeks \\
\hline $\begin{array}{c}\text { FEITOSA et } \\
\text { al.31 }\end{array}$ & Sheep & - & $\begin{array}{l}\text { Bone necrosis } \\
\text { from histology } \\
\text { of the femoral } \\
\text { head }\end{array}$ & - & 4 weeks \\
\hline
\end{tabular}




\begin{tabular}{|c|c|c|c|c|c|}
\hline $\begin{array}{l}\text { CHAN et } \\
\text { al.32 }\end{array}$ & $\begin{array}{l}\text { Immunological } \\
\text { mice }\end{array}$ & $\begin{array}{c}\text { Nanofiber } \\
\text { materials bind } \\
\text { their peptides } \\
\text { together }\end{array}$ & $\begin{array}{l}\text { Subcutaneous } \\
\text { transplantation }\end{array}$ & $\begin{array}{l}\text { Histology, X-ray and } \\
\text { immunohistochemistry }\end{array}$ & 4 weeks \\
\hline $\begin{array}{l}\text { IKEDA et } \\
\quad \text { al.33 }\end{array}$ & $\begin{array}{l}\text { Immunological } \\
\text { mice }\end{array}$ & HA granules & $\begin{array}{l}\text { Subcutaneous } \\
\text { transplantation }\end{array}$ & $\begin{array}{c}\text { Histology and } \\
\text { histomorphometry }\end{array}$ & 8 weeks \\
\hline LI et al.34 & $\begin{array}{l}\text { Immunological } \\
\text { mice }\end{array}$ & $\begin{array}{l}\text { 3D gelatin } \\
\text { scaffolding } \\
\text { (Three- } \\
\text { dimensional) }\end{array}$ & $\begin{array}{l}\text { Subcutaneous } \\
\text { transplantation }\end{array}$ & $\begin{array}{l}\text { Histology, X-ray and } \\
\text { immunohistochemistry }\end{array}$ & 4 weeks \\
\hline $\begin{array}{l}\text { PISCIOTTA } \\
\text { et al.35 }\end{array}$ & Rat & $\begin{array}{l}\text { Collagen } \\
\text { scaffold }\end{array}$ & Skull defects & $\begin{array}{l}\text { Histology } \\
\text { Immunohistochemistry } \\
\text { and histomorphometry }\end{array}$ & 6 weeks \\
\hline ABE et al.36 & $\begin{array}{l}\text { Immunological } \\
\text { mice }\end{array}$ & HA scaffolding & $\begin{array}{l}\text { Subcutaneous } \\
\text { transplantation }\end{array}$ & $\begin{array}{l}\text { Histology and } \\
\text { immunofluorescence }\end{array}$ & 12 weeks \\
\hline $\begin{array}{l}\text { CHEN et } \\
\text { al.37 }\end{array}$ & $\begin{array}{l}\text { Immunological } \\
\text { mice }\end{array}$ & $\begin{array}{l}\text { HA / TCP } \\
\text { scaffolding }\end{array}$ & $\begin{array}{l}\text { Subcutaneous } \\
\text { transplantation }\end{array}$ & $\begin{array}{c}\text { Histology } \\
\text { Histomorphometry and } \\
\text { clinical evaluation }\end{array}$ & 12 weeks \\
\hline $\begin{array}{c}\text { KAWANABE } \\
\text { et al.38 }\end{array}$ & $\begin{array}{l}\text { Immunological } \\
\text { mice }\end{array}$ & B-TCP scaffold & $\begin{array}{l}\text { Subcutaneous } \\
\text { transplantation }\end{array}$ & $\begin{array}{c}\text { Histology and } \\
\text { immunohistochemistry }\end{array}$ & 8 weeks \\
\hline $\begin{array}{c}\text { WANG et } \\
\text { al.39 }\end{array}$ & $\begin{array}{l}\text { Immunological } \\
\text { mice }\end{array}$ & - & $\begin{array}{l}\text { Subcutaneous } \\
\text { transplantation }\end{array}$ & $\begin{array}{c}\text { Histology and clinical } \\
\text { evaluation }\end{array}$ & 8 weeks \\
\hline $\begin{array}{c}\text { BRESSAN et } \\
\text { al.40 }\end{array}$ & $\begin{array}{l}\text { Immunological } \\
\text { mice }\end{array}$ & HA scaffolding & Eye defects & $\begin{array}{c}\text { Histology and real-time } \\
\text { PCR }\end{array}$ & 3 weeks \\
\hline $\begin{array}{l}\text { RICCIO et } \\
\text { al.41 }\end{array}$ & Rat & $\begin{array}{c}\text { Fibrin } \\
\text { scaffolding }\end{array}$ & Skull defects & $\begin{array}{l}\text { Histology, X-ray and } \\
\text { immunohistochemistry }\end{array}$ & 4 weeks \\
\hline $\begin{array}{l}\text { ANNIBALI } \\
\text { et al.42 }\end{array}$ & $\begin{array}{l}\text { Immunological } \\
\text { mice }\end{array}$ & $\begin{array}{c}\beta \text {-TCP, GDPPB } \\
\text { and calorie } \\
\text { deficiency of } \\
\text { agar / NHA }\end{array}$ & - & $\begin{array}{c}\text { Histology and } \\
\text { histomorphometry }\end{array}$ & $\begin{array}{l}1,2,4,8 \\
\text { weeks }\end{array}$ \\
\hline $\begin{array}{c}\text { El-GENDY et } \\
\text { al.43 }\end{array}$ & $\begin{array}{l}\text { Immunological } \\
\text { mice }\end{array}$ & $\begin{array}{l}\text { BIOGLASS }(\mathrm{R}) \\
\text { 3D scaffolding }\end{array}$ & $\begin{array}{l}\text { Intravenous } \\
\text { transplant }\end{array}$ & $\begin{array}{c}\text { Histology and } \\
\text { immunohistochemistry }\end{array}$ & 8 weeks \\
\hline $\begin{array}{c}\text { MARALDI et } \\
\text { al.44 }\end{array}$ & $\begin{array}{l}\text { Immunological } \\
\text { mice }\end{array}$ & $\begin{array}{l}\text { Collagen } \\
\text { scaffold }\end{array}$ & Skull defects & $\begin{array}{l}\text { Histology, X-ray, } \\
\text { Immunohistochemistry } \\
\text { and histomorphometry }\end{array}$ & 4,8 weeks \\
\hline $\begin{array}{l}\text { ALKAISI et } \\
\text { al.45 }\end{array}$ & Rabbit & - & $\begin{array}{l}\text { Mandibular } \\
\text { bone defects }\end{array}$ & $\begin{array}{c}\text { Histological } \\
\text { histomorphometry and } \\
\text { radiological and clinical } \\
\text { evaluation }\end{array}$ & 2,4,6 weeks \\
\hline $\begin{array}{c}\text { GIULIANI et } \\
\text { al.46 }\end{array}$ & Human & Collagen sponge & $\begin{array}{l}\text { Third mill tooth } \\
\text { extraction defect }\end{array}$ & $\begin{array}{c}\text { Histology, } \\
\text { Histomorphometry, } \\
\text { Phasectronant } \\
\text { Microtomography, } \\
\text { Synchrotron X-ray, } \\
\text { Clotomography and } \\
\text { Clinical and clinical } \\
\text { evaluation }\end{array}$ & $\begin{array}{c}6 \\
\text { months/ } 1,3 \\
\text { years }\end{array}$ \\
\hline NIU et al.47 & $\begin{array}{l}\text { Immunological } \\
\text { mice }\end{array}$ & NSC and ISCS & $\begin{array}{l}\text { Subcutaneous } \\
\text { transplantation }\end{array}$ & $\begin{array}{l}\text { Histology and } \\
\text { immunohistochemistry }\end{array}$ & 8 weeks \\
\hline $\begin{array}{c}\text { ACASIGUA } \\
\text { et al.48 }\end{array}$ & Rat & $\begin{array}{c}\text { PLGA } \\
\text { scaffolding }\end{array}$ & Eye defects & $\begin{array}{c}\text { Histology and } \\
\text { histomorphometry }\end{array}$ & 60 days \\
\hline $\begin{array}{l}\text { ANNIBALI } \\
\text { et al.49 }\end{array}$ & $\begin{array}{l}\text { Immunological } \\
\text { mice }\end{array}$ & $\begin{array}{l}\text { Scaffolding } \\
\text { GDPB and } \beta \text { - } \\
\text { TCP }\end{array}$ & Eye defects & $\begin{array}{c}\text { Microsystem tomography } \\
2,4,8 \text { and } \\
\text { And positron emission }\end{array}$ & 12 weeks \\
\hline KIM et al.50 & $\begin{array}{l}\text { Immunological } \\
\text { mice }\end{array}$ & $\begin{array}{c}\text { MBCP } \\
\text { scaffolding }\end{array}$ & $\begin{array}{l}\text { Subcutaneous } \\
\text { transplantation }\end{array}$ & $\begin{array}{c}\text { Histology } \\
\text { Immunohistochemistry, } \\
\text { prompt PCR and ELISA }\end{array}$ & 8 weeks \\
\hline $\begin{array}{c}\text { ASUTAY et } \\
\text { al.51 }\end{array}$ & Rat & Paste HA / TCP & Eye defects & $\begin{array}{l}\text { Histology } \\
\text { Histomorphometry and } \\
\text { microscopic computed } \\
\text { tomography }\end{array}$ & 8 weeks \\
\hline
\end{tabular}


40 Regulation of gene expression in tissue engineering...

\begin{tabular}{|c|c|c|c|c|c|}
\hline CAO et al.52 & Small pigs & $\begin{array}{l}\text { HA / TCP } \\
\text { scaffolding }\end{array}$ & $\begin{array}{l}\text { Periodontal bone tissue } \\
\text { defects } \\
\text { HISTOMORPHOMETRY }\end{array}$ & $\begin{array}{c}\text { Assessment } \\
\text { Radiological and } \\
\text { clinical }\end{array}$ & $\begin{array}{c}12 \\
\text { weeks }\end{array}$ \\
\hline KUO et al.53 & Small pigs & $\begin{array}{c}\text { Scaffolding } \\
\text { CSD, } \alpha \text {-CSH } \\
\text { / ACP and } \beta- \\
\text { TCP }\end{array}$ & $\begin{array}{l}\text { Mandibular bone defects } \\
\text { and defects } \\
\text { Histomorphometry }\end{array}$ & - & $\begin{array}{c}8 \\
\text { weeks }\end{array}$ \\
\hline $\begin{array}{l}\text { QIAN et } \\
\text { al.54 }\end{array}$ & $\begin{array}{l}\text { Immunological } \\
\text { mice }\end{array}$ & $\begin{array}{l}\text { HA / TCP } \\
\text { scaffolding }\end{array}$ & $\begin{array}{l}\text { Subcutaneous } \\
\text { histomorphometry }\end{array}$ & $\begin{array}{l}\text { Histology and } \\
\text { implantation }\end{array}$ & $\begin{array}{c}2,3 \\
\text { month } \\
\mathrm{s}\end{array}$ \\
\hline $\begin{array}{l}\text { PETRIDIS et } \\
\text { al.55 }\end{array}$ & Rat & $\begin{array}{l}\text { HA-based } \\
\text { hydrogel } \\
\text { scaffolding }\end{array}$ & Eye defects & $\begin{array}{c}\text { Histology and } \\
\text { histomorphometry }\end{array}$ & $\begin{array}{c}8 \\
\text { weeks }\end{array}$ \\
\hline $\begin{array}{l}\text { KWON et } \\
\text { al.56 }\end{array}$ & Rat & $\begin{array}{l}\text { Scaffolding } \\
\text { made by } \\
\text { computer }\end{array}$ & Skull defects & $\begin{array}{l}\text { Histology and } \\
\text { micromechanical } \\
\text { tomography }\end{array}$ & $\begin{array}{l}4,8,12 \\
\text { weeks }\end{array}$ \\
\hline $\begin{array}{l}\text { JANG et } \\
\text { al.57 }\end{array}$ & Rat & $\begin{array}{l}\text { Hydrogel } \\
\text { formation in } \\
\text { vivo }\end{array}$ & $\begin{array}{l}\text { Subcutaneous } \\
\text { transplantation }\end{array}$ & $\begin{array}{l}\text { Histology, reverse } \\
\text { transcription PCR and } \\
\text { microscopic computed } \\
\text { tomography }\end{array}$ & $\begin{array}{c}2,4,6 \\
\text { weeks }\end{array}$ \\
\hline $\begin{array}{l}\text { JAHANBIN } \\
\text { et al.58 }\end{array}$ & Rat & $\begin{array}{l}\text { Collagen } \\
\text { matrix }\end{array}$ & Jaw bone defect & $\begin{array}{l}\text { Histology and } \\
\text { histomorphometry }\end{array}$ & $\begin{array}{c}1,2 \\
\text { month } \\
\mathrm{s}\end{array}$ \\
\hline $\begin{array}{l}\text { YASUI et } \\
\text { al.59 }\end{array}$ & $\begin{array}{l}\text { Immunological } \\
\text { mice }\end{array}$ & $\begin{array}{c}\text { Matrix } \\
\text { scaffolding } \\
\text { MATRIGEL }\end{array}$ & Eye defects & $\begin{array}{l}\text { Immunohistochemistry } \\
\text { and microscopic } \\
\text { computed tomography }\end{array}$ & $\begin{array}{c}4 \\
\text { weeks }\end{array}$ \\
\hline $\begin{array}{l}\text { MONTI et } \\
\text { al.60 }\end{array}$ & Human & $\begin{array}{l}\text { Collagen } \\
\text { sponge }\end{array}$ & $\begin{array}{l}\text { Third mill tooth extraction } \\
\text { defect }\end{array}$ & $\begin{array}{l}\text { Histology and } \\
\text { radiology }\end{array}$ & $\begin{array}{l}60 \text {-day } \\
\text { evalua } \\
\text { tion }\end{array}$ \\
\hline $\begin{array}{l}\text { WONGSUP } \\
\text { A et al.61 }\end{array}$ & Rabbit & $\begin{array}{l}\text { Scaffolding } \\
\text { PCL-BCP }\end{array}$ & Eye defects & $\begin{array}{c}\text { Histology, } \\
\text { histomorphometry, } \\
\text { microsomal } \\
\text { tomography and } \\
\text { clinical evaluation }\end{array}$ & $\begin{array}{c}2,4,8 \\
\text { weeks }\end{array}$ \\
\hline $\begin{array}{l}\text { PAINO et } \\
\text { al.62 }\end{array}$ & $\begin{array}{l}\text { Immunological } \\
\text { mice }\end{array}$ & $\begin{array}{l}\text { Bone } \\
\text { subcutaneous } \\
\text { tissue is } \\
\text { made by } \\
\text { HDPSCs }\end{array}$ & Mandibular bone defects & $\begin{array}{c}\text { Histology } \\
\text { Immunofluorescence, } \\
\text { X-ray } \\
\text { microtomography, } \\
\text { Synchrotron } \\
\text { enterographic factor, } \\
\text { and holotomography }\end{array}$ & $\begin{array}{c}30,40 \\
\text { days }\end{array}$ \\
\hline MA et al.63 & $\begin{array}{l}\text { Immunological } \\
\text { mice }\end{array}$ & $\begin{array}{l}\text { Scaffolding } \\
\text { HA / TCP }\end{array}$ & $\begin{array}{l}\text { CALVARIAL defect, } \\
\text { subcutaneous implantation } \\
\text { and intravenous injection }\end{array}$ & $\begin{array}{l}\text { Histology, ELISA and } \\
\text { immunofluorescence }\end{array}$ & $\begin{array}{c}4,8 \\
\text { weeks }\end{array}$ \\
\hline LIU et al.64 & $\begin{array}{l}\text { Immunological } \\
\text { mice }\end{array}$ & - & Intravenous injection & $\begin{array}{l}\text { Histology, ELISA } \\
\text { histomorphometry and } \\
\text { microscopic computed } \\
\text { tomography }\end{array}$ & $\begin{array}{c}8 \\
\text { weeks }\end{array}$ \\
\hline $\begin{array}{l}\text { BEHNIA et } \\
\text { al.65 }\end{array}$ & Dogs & $\begin{array}{l}\text { Collagen } \\
\text { scaffold }\end{array}$ & Mandibular bone defects & $\begin{array}{l}\text { Histology, clinical } \\
\text { evaluation and image } \\
\text { segmentation }\end{array}$ & $\begin{array}{c}12 \\
\text { weeks }\end{array}$ \\
\hline $\begin{array}{l}\text { JEON et } \\
\text { al.66 }\end{array}$ & $\begin{array}{l}\text { Immunological } \\
\text { mice }\end{array}$ & $\begin{array}{c}\text { MBCP } \\
\text { scaffolding }\end{array}$ & $\begin{array}{l}\text { Subcutaneous } \\
\text { transplantation }\end{array}$ & $\begin{array}{c}\text { Histology } \\
\text { Immunohistochemistry, } \\
\text { QPCR, and quantitative } \\
\text { testing of alkaline } \\
\text { phosphatase levels }\end{array}$ & $\begin{array}{c}9 \\
\text { weeks }\end{array}$ \\
\hline MA et al.67 & Mouse & - & Intravenous injection & $\begin{array}{l}\text { Histology, ELISA, } \\
\text { real-time RT-PCR and } \\
\text { electron microscopy }\end{array}$ & $\begin{array}{c}4 \\
\text { weeks }\end{array}$ \\
\hline
\end{tabular}




\begin{tabular}{|c|c|c|c|c|c|}
\hline $\begin{array}{l}\text { FENG et } \\
\text { al.68 }\end{array}$ & Rabbit & - & $\begin{array}{l}\text { Bone defects } \\
\text { TIBIAL }\end{array}$ & $\begin{array}{c}\text { Histology, microsomal } \\
\text { tomography, } \\
\text { radiography, dual } \\
\text { energy X-ray } \\
\text { absorption and } \\
\text { mechanical evaluation }\end{array}$ & 8 weeks \\
\hline LI et al.69 & Human & B-TCP scaffold & $\begin{array}{l}\text { Periodontal } \\
\text { bone defects }\end{array}$ & $\begin{array}{c}\text { Clinical and radiological } \\
\text { evaluation }\end{array}$ & $1,3,9$ months \\
\hline $\begin{array}{l}\text { HILKENS } \\
\text { et al.70 }\end{array}$ & $\begin{array}{l}\text { Immunological } \\
\text { mice }\end{array}$ & $\begin{array}{l}\text { HA scaffolding } \\
\text { printed with 3D }\end{array}$ & $\begin{array}{l}\text { Subcutaneous } \\
\text { transplantation }\end{array}$ & $\begin{array}{l}\text { Histology and scanning } \\
\text { electron microscopy }\end{array}$ & 12 weeks \\
\hline $\begin{array}{l}\text { KANG et } \\
\text { al.71 }\end{array}$ & $\begin{array}{l}\text { Immunological } \\
\text { mice }\end{array}$ & $\begin{array}{c}\text { Granules } \\
\text { HA / TCP and } \\
\text { DDM }\end{array}$ & $\begin{array}{l}\text { Subcutaneous } \\
\text { transplantation }\end{array}$ & $\begin{array}{l}\text { Histology } \\
\text { Immunohistochemistry, } \\
\text { QRTPCR and } \\
\text { microscopic computed } \\
\text { tomography }\end{array}$ & 1,8 weeks \\
\hline $\begin{array}{l}\text { SEO et } \\
\text { al.72 }\end{array}$ & $\begin{array}{l}\text { Immunological } \\
\text { mice }\end{array}$ & $\begin{array}{l}\text { HA / TCP } \\
\text { scaffolding }\end{array}$ & Eye defects & $\begin{array}{c}\text { Histology, } 6 \text { and } 8 \text { weeks } \\
\text { or } \\
\text { immunohistochemistry, } \\
\text { 6-month in situ } \\
\text { hybridization and RT- } \\
\text { PCR }\end{array}$ & - \\
\hline
\end{tabular}

\section{Transcriptional regulators}

Transcription factors are protein complexes that participate in regulating gene position and controlling gene expression in NSCs. The diversity in these complexes regulates the final cell phenotype of NSCs. Among the transcription factors, the nuclear Tlx receptor is essential for the maintenance of neuronal stem cells and the self-regeneration of NSCs. The Tlx gene is expressed in sensory neurons as well as postsynaptic neurons. In addition, Tlx3 expression along with two other transcription factors, Phox $2 b$ and DRG11, leads to the distinction between two somatic sense circuits (Tlx3 +, DRG1+) from visceral sense circuits $(\mathrm{Tlx} 3+$, Phox $2 \mathrm{~b}+$ ). Tlx shows strong but the scattered expression in the subgranular zone ${ }^{8}$, Gadolinium $^{9}$, and the Subventricular Zone ${ }^{10}$, and in the formation of superficial membrane layers in the embryonic brain Nerve (neurogenesis) is effective (30). The main function of TLX in the adult brain is to prevent premature differentiation of NSC by controlling the expression of a wide array of genes. In this method, TLX; It keeps NSCs undifferentiated and selfrenewable, thereby modulating P53 pathway signaling $(31,60)$.

\section{Epigenetic control}

The skeletal microstructure of extracellular matrix units of bone includes; Osteocytes, Osteoblasts, Osteoclasts, and liner cells are formed (32). The function of
Osteoclasts and Osteoblasts is very important in maintaining and repairing bones. Bone regeneration is a lifelong process in which new bone tissue is formed and mature bone tissue is reabsorbed (33). Imbalances in bone formation and bone resorption can lead to bone metabolic diseases. Osteoporosis can occur if the process of bone resorption is faster than the formation of new bone (34). Osteoporosis is a multifactorial disease that can be regulated by both genetic and environmental factors. In addition to genetic factors, behaviors such as low levels of physical activity, smoking, and caffeine consumption along with nutrients (including dietary calcium intake and vitamin D deficiency) are important determinants of osteoporosis and bone fractures. Evidence suggests that epigenetic modifications can be considered as key mechanisms for linking genetic and environmental factors to the risk of osteoporosis $(38,37)$. Using genome-related studies, several studies on the genetic risks of osteoporosis have been performed to assess bone mineral density (BMD) as quantitative traits (35). It has been reported more than 60 genes were associated with BMD and the incidence of osteoporosis (36).

Epigenetic modifications can control the transcription process, resulting in self-regeneration and differentiation of stem cells. Epigenetic spatial and temporal methods are effective during the development and differentiation of neuronal stem cells into adult neurons. One of these methods is histone deacetylases, which are involved in regulating differentiation by inhibiting stem cells auto regeneration transcription. REST $^{11}$ increases the expression of specific neuronal genes by regulating transcription. In non-neural cells, it also uses HDAC complexes with its cofactors such as Co-REST, N-CoR,

${ }^{11}$ transcription factor RE1 
and $\mathrm{mSin} 3 \mathrm{~A}$ to inhibit the expression of neural genes through epigenetic regulation (39).

Methylation is an epigenetic marker and is dependent on transcriptional activation and inhibition (40). At the epigenetic DNA level, it is regulated by methylation, and its most prominent form is the symmetric methylation of cytosine in the 5' region of $\mathrm{CpG}$ dinucleotides. It has a definite role in regulating the transcription of the DNA methylation gene and its chromatin-related rearrangement $(31,60)$.

\section{miRNA regulators}

Stem cells are undifferentiated cells and have the potential for multilinear differentiation. Stem cells are generally referred to as adult stem cells, embryonic stem cells (ESCs), and pluripotent stem cells (iPSCs). Adult stem cells are named according to the tissue in which they are formed, such as mesenchymal stem cells (MSCs), hematopoietic stem cells (HSCs), cardiac stem cells, nerve stem cells (NSCs), cells Endothelial stem cells, and etc. Embryonic stem cells (ESCs) are pluripotent and are derived from the inner cells mass of the blastocyst or Morula precursor embryos (41), whereas iPSCs are produced directly by somatic cells programming. Stem cells have high potential due to their potency and ability to regenerate in clinical treatments (42).

MicroRNAs (miRNAs) are small, non-coding singlestranded RNAs about 21-22 nucleotides long in length that suppress gene expression by inhibiting translation or by promoting mRNA degradation. In the nucleus, primary miRNAs ${ }^{12}$ are transcribed to form precursor miRNAs, derived from the DGCR8 RNA binding protein and the enzyme RNase III Drosha. miRNAs enter the cytoplasm and are eventually processed by Dicer to produce adult miRNAs (43). Studies have shown that miRNAs play an important role in the physiological processes and pathogenesis of many diseases. miRNAs are important regulators of stem cells. Studies show that miRNAs regulate stem cells status by directly targeting $3 \%$ UTR. In addition, miRNAs target regions encoding transcription factors to modulate stem cells differentiation. Other classified miR-miRNAs also, regulate the fate of stem cells; Embryonic stem cellspecific miRNAs (ESCs) (also, called ESC-specific cell cycle-regulating miRNAs), C-Myc-derived miRNAs, p53 miRNAs, and self-regenerating primary embryonic miRNAs ${ }^{13}$, reprogramming and regulate stem cells differentiation $(44,45)$.

\section{miRNAs and stem cell potency}

miRNAs have the ability to modulate stem cells and generally regulate potency enhancers by directly targeting UTR-3'. miR-145 suppresses the potency of human ESCs, by suppressing the expression of Oct4, Sox2, and Klf4 (46). However, miR-134, miR-296, and miR-470 target the Sox2, Nanog, and Oct4 coding sequences to power ESCs (47). Studies have shown that the miR-290 family affects the strength and differentiation of ESCs through epigenetic regulation of DNA de novo methylation (48). Another study showed that the transcription factors Sox2, nanog, and transcription factor 3 (Tcf3), with binding sites in the promoter region of most miRNAs, were expressed exclusively in ESCs. These transcription factors also, regulate the expression of miRNAs (49).

\section{miRNAs modulate bone marrow stem cell differentiation}

Significant advances have been made in the production of osteogenic cells from adult stem cells. miRNAs regulate bone and chondrogenic differentiation by targeting important transcription factors and relative pathways during skeletal maturation. The ERKdependent pathway plays an important role in bone differentiation. It can activate second-order transcription factor phosphorylation (RUNX2), enhance osterix expression, and improve alkaline phosphatase activity. miR-138 suppresses the differentiation of human mesenchymal stem cells into osteoblasts by directly targeting FAK (50). miR-23b induces differentiation of human mesenchymal stem cells by suppressing signaling protein kinase A PKA (51).

12 PR-miRNAs

13 EEmiRCs 
Table 2.

\begin{tabular}{|c|c|c|c|}
\hline mRNA & function & purpose & Reference \\
\hline miRNA-29a & $\begin{array}{l}\text { regulates cartilage } \\
\text { differentiation and } \\
\text { cartilage formation }\end{array}$ & FOXO3A & 52 \\
\hline microRNA-145 & $\begin{array}{l}\text { Power suppression in } \\
\text { human ESCs }\end{array}$ & Oct4, Sox2, Klf4 & 46 \\
\hline miR-23b & $\begin{array}{lr}\text { Makes } & \text { cartilage } \\
\text { differentiation } & \text { from } \\
\text { HMSC } & \\
\end{array}$ & $\begin{array}{l}\text { Suppression of PKA } \\
\text { signaling with } \\
\text { Daam1 and ROCK1 }\end{array}$ & 50 \\
\hline miR-138 & $\begin{array}{l}\text { Osteoblast differentiation } \\
\text { suppresses } \\
\text { mesenchymal stem cells }\end{array}$ & FAK targeting & 51 \\
\hline $\begin{array}{l}\text { MiR-290 family or } \\
\text { MiR-302 family }\end{array}$ & $\begin{array}{l}\text { increases programming } \\
\text { efficiency }\end{array}$ & Oct4, Sox2, Klf4 & 53 \\
\hline Human miR-372 & $\begin{array}{l}\text { Improves planning } \\
\text { efficiency }\end{array}$ & - & 58 \\
\hline $\begin{array}{l}\text { miR-17-92 cluster, miR- } \\
106 b-25 \text { cluster, miR- } \\
106 a-363 \text { cluster }\end{array}$ & $\begin{array}{l}\text { improves scheduling } \\
\text { efficiency }\end{array}$ & TGF- $\beta$ R2, p21 & 59 \\
\hline
\end{tabular}

\section{SOX family}

The sox factor family belongs to the SRY ${ }^{14}$ gene family and has a high mobility group (HMG) region that binds to DNA, which is very similar to the sry-box of the HMG-Box of the sox protein family. The DNA-binding region consists of three alpha HMG-Box helixes that occurs specifically in the small DNA groove of this binding and provide a strong curve that changes the DNA architecture. These changes allow them to interact with other transcription factors. Members of the sox family interact in a wide range of cellular tissues, resulting in a variety of effects on cellular metabolism. In invertebrates, soxb1 (sox1, sox2, sox3) factors are widely expressed in proliferating stem cells / proliferating neurons during development and maturation (57).

\section{Conclusion}

According to the results, it can be concluded that many genes are involved in different stages of expression of genes involved in the formation of bone tissue, each of which can play many roles in the formation, repairment, or termination of the agent. Negatively involved in the execution of a particular gene.

\section{Acknowledgments}

The authors thank Royan Research Institute for resources and support. 
44 Regulation of gene expression in tissue engineering...

\section{References}

1.Liu, J., et al. (2016). "Development of nanocellulose scaffolds with tunable structures to support 3D cell culture." Carbohydrate polymers 148: 259-271.

2.Greiner, A. M., et al. (2012). "Micro-engineered 3D scaffolds for cell culture studies." Macromolecular bioscience 12(10): 1301-1314.

3.Santos, E., et al. (2012). "Novel advances in the design of three-dimensional bio-scaffolds to control cell fate: translation from 2D to 3D." Trends in Biotechnology 30(6): 331-341.

4.Edmondson, R., et al. (2014). "Three-dimensional cell culture systems and their applications in drug discovery and cell-based biosensors." Assay and drug development technologies 12(4): 207-218.

5.Shamir, E. R., and A. J. Ewald (2014). "Threedimensional organotypic culture: experimental models of mammalian biology and disease." Nature reviews Molecular cell biology 15(10): 647.

6.J Sawkins, M., et al. (2013). "3D cell and scaffold patterning strategies in tissue engineering." Recent Patents on Biomedical Engineering 6(1): 3-21.

7.Wu, J., et al. (2017). "Recent advances in microfluidic 3D cellular scaffolds for drug assays." TrAC Trends in Analytical Chemistry 87: 19-31.

8.Shim, K., et al. (2017). "Fabrication of micrometerscale porous gelatin scaffolds for 3D cell culture." Journal of Industrial and Engineering Chemistry 50: 183-189.

9.Ronca, D., et al. (2016). "Bone tissue engineering: 3D PCL-based nanocomposite scaffolds with tailored properties." Procedia Cirp 49: 51-54

10.Tan, Z., et al. (2017). "Control of cell growth on 3D-printed cell culture platforms for tissue engineering." Journal of Biomedical Materials Research Part A 105(12): 3281-3292.

11.Sun, Y., et al. (2016). "Novel compound-forming technology using bioprinting and electrospinning for patterning a 3D scaffold construct with multiscale channels." Micromachines 7(12): 238.

12.Lee, S. J., et al. (2016). "Surface modification of 3Dprinted porous scaffolds via mussel-inspired polydopamine and effective immobilization of rhBMP-2 to promote osteogenic differentiation for bone tissue engineering." Acta biomaterialia 40: 182-191.

13.Kantaros, A., et al. (2016). "3D printing-assisted design of scaffold structures." The International Journal of Advanced Manufacturing Technology 82(1-4): 559571.

14.An, J., et al. (2015). "Design and 3D printing of scaffolds and tissues." Engineering 1(2): 261-268.

15.Bose, S., et al. (2013). "Bone tissue engineering using 3D printing." Materials today 16(12): 496-504.

16.Lima, M., et al. (2014). "Micro/nano replication and 3D assembling techniques for scaffold fabrication." Materials Science and Engineering: C 42: 615-621.

17.Yuan, H., et al. (2018). "Trinity of three-dimensional (3d) scaffold, vibration, and 3d printing on cell culture application: A systematic review and indicating future direction." Bioengineering 5(3): 57.

18.Thompson WR, Gottardi R, Stearns KM, Rubin J, Ambrosio F, Tuan RS. Biologics in cartilage, bone repair, and regeneration. In: Hughes CC, Childers M, editors. Appl Regen Med to Orthop Phys Ther. La Crosse: Orthopaedic Section: APTA; 2014. p. 1-24

19.Laurencin CT, Ambrosio AMA, Borden MD, Cooper JA. Tissue engineering: Orthopedic applications. Annu Rev Biomed Eng. 1999;1:19-46.

20.Cowin SC, Cardoso L. Blood, and interstitial flow in the hierarchical pore space architecture of bone tissue. J Biomech. 2015;48:842-854.

21.Yang Y. Skeletal morphogenesis during embryonic development. Crit Rev Eukaryot Gene Expr. 2009;19:197-218.

22.Fröhlich M, Grayson WL, Wan LQ, Marolt D, Drobnic M, Vunjak-Novakovic G. Tissue engineered bone grafts: biological requirements, tissue culture, and clinical relevance. Curr Stem Cell Res Ther. 2008;3:254-264.

23.Chung AS, Ferrara N. Developmental and pathological angiogenesis. Annu Rev Cell Dev Biol. 2011;27:563-584.

24.Ferrara N, Gerber H-P, LeCouter J. The biology of VEGF and its receptors. Nat Med. 2003;9:669-676.

25.Braghirolli DI, Helfer VE, Chagastelles PC, Dalberto TP, Gamba D, Pranke P. Electrospun scaffolds functionalized with heparin and vascular endothelial growth factor increase the proliferation of endothelial progenitor cells. Biomed Mater. 2017;12:25003.

26. Wittkowske C, Reilly GC, Lacroix D, Perrault CM. In vitro bone cell models: impact of fluid shear stress on bone formation. Front Bioeng Biotechnol. 2016;4:87.

27.Alliston T. Biological regulation of bone quality. Curr Osteoporos Rep. 2014;12:366-375.

28.Dallas SL, Prideaux M, Bonewald LF. The osteocyte: an endocrine cell ... and more. Endocr Rev. 2013;34:658-690.

29.Bruzzaniti A, Baron R. Molecular regulation of osteoclast activity. Rev Endocr Metab Disord. 2006; 7:123-139.

30.Shi Y, Sun G, Zhao C, Stewart R. Neural stem cell self-renewal. Crit Rev Oncol Hematol. 2008; 65: 43-53.

31.Quiroz, E.N, et al. (2018). "cell signaling in neuronal stem cell" cells 7(7):75.

32.Schuiling, K. D., et al. (2011). "Osteoporosis update." Journal of midwifery \& women's health 56(6): 615-627. 
33.Sobacchi, C., et al. (2013). "Osteopetrosis: genetics, treatment, and new insights into osteoclast function." Nature Reviews Endocrinology 9(9): 522.

34.Wu, S., et al. (2013). "Genome-wide approaches for identifying genetic risk factors for osteoporosis." Genome medicine 5(5): 44.

35.Mori, S. (2016). "Genome-wide association study for Osteoporosis." Clinical calcium 26(4): 537-543.

36.Kung, A. W., and Q. Huang (2007). "Genetic and environmental determinants of osteoporosis." Journal of Musculoskeletal and Neuronal Interactions 7(1): 26.

37.Yasui, T., et al. (2011). "Epigenetic regulation of osteoclast differentiation." Annals of the New York Academy of Sciences 1240(1): 7-13.

38.Ghayor C. and Weber F.E. (2016) Epigenetic regulation of bone remodeling and its impacts in osteoporosis. Int. J. Mol. Sci. 17, 1-14, 10.3390/ijms 17091446.

39.Ballas N, Grunseich C, Lu DD, Speh JC, Mandel G.REST, and its corepressors mediate plasticity of neuronal gene chromatin throughout neurogenesis. J Cell. 2005; 121: 645-57

40.Kouzarides T. Chromatin modifications and their function. J Cell. 2007; 128: 693-705.

41.Evans MJ, Kaufman MH. Establishment in culture of pluripotential cells from mouse embryos.Nature. 1981;292:154-6. doi: 10.1038/292154a0

42.Takahashi K, Yamanaka S. Induction of pluripotent stem cells from mouse embryonic and adult fibroblast cultures by defined factors. Cell. 2006;126(4):66376.doi:10.1016/j.cell.2006.07.024

43.Lund E, et al. Nuclear export of microRNA precursors. Science. 2004;303(5654):95-8. doi: 10.1126/science.1090599

44.Wang Y, et al. Embryonic stem cell-specific microRNAs regulate the G1-S transition and promote rapid proliferation. Nat Genet. 2008;40(12):1478-83. doi: $10.1038 / \mathrm{ng} .250$.

45.Tata PR, et al. Identification of a novel epigenetic regulatory region within the pluripotency associated microRNA cluster, EEmiRC. Nucleic Acids Res. 2011;39(9):3574-81. doi: 10.1093/nar/gkq1344.

46.Xu N, et al. MicroRNA-145 Regulates OCT4, SOX2, and KLF4 and represses pluripotency in human embryonic stem cells. Cell. 2009;137(4):647-58. doi: 10.1016/j.cell.2009.02.038.

47. Tay Y, et al. MicroRNAs to Nanog, Oct4, and Sox2 coding regions modulate embryonic stem cell differentiation. Nature. 2008;455(7216):1124-8. doi: 10.1038/nature07299.

48. Sinkkonen L, et al. MicroRNAs control de novo DNA methylation through regulation of transcriptional repressors in mouse embryonic stem cells. Nat Struct Mol Biol. 2008;15(3):259-67. doi: 10.1038/nsmb.1391.

49.Marson A, et al. Connecting microRNA genes to the core transcriptional regulatory circuitry of embryonic stem cells. Cell. 2008;134(3):521-33. doi: 10.1016/j.cell.2008.07.020.

50.Eskildsen $\mathrm{T}$, et al. MicroRNA-138 regulates osteogenic differentiation of human stromal (mesenchymal) stem cells in vivo. Proc Natl Acad Sci U S A. 2011;108(15):6139-44. doi: 10.1073/pnas.1016758108.

51.Ham O, et al. The role of microRNA-23b in the differentiation of MSC into chondrocyte by targeting protein kinase A signaling. Biomaterials. 2012;33(18):4500-7.

10.1016/j.biomaterials.2012.03.025.

52.Guerit D, et al. FOXO3A regulation by miRNA-29a Controls chondrogenic differentiation of mesenchymal stem cells and cartilage formation. Stem Cells Dev. 2014;23(11):1195-205. doi: 10.1089/scd.2013.0463.

53.Judson RL, et al. Embryonic stem cell-specific microRNAs promote induced pluripotency. Nat Biotechnol. 2009;27(5):459-61. doi: 10.1038/nbt.1535.

54.Mattick JS, Makunin IV. Small regulatory RNAs in mammals. Hum Mol Genet. 2005; 14: 121-3

55.Smirnova L, Gräfe A, Seiler A, Schumacher S, Nitsch R, Wulczyn FG. Regulation of miRNA expression during neural cell specification. Eur J Neurosci. 2005; 21: 1469-77.

56.Visvanathan J, Lee S, Lee B, Lee JW, Lee SK. The microRNA miR-124 antagonizes the anti-neural REST/SCP1 pathway during embryonic CNS development. Genes. 2007; 21: 744-9

57.Bylund M, Andersson E, Novitch BG, Muhr J. Vertebrate neurogenesis is counteracted by Sox 1-3 activity. Nat Neurosci. 2003; 11: 1162-8.

58.Subramanyam D, et al. Multiple targets of miR-302 and miR-372 promote reprogramming of human fibroblasts to induced pluripotent stem cells. Nat Biotechnol. 2011;29:443-9. doi: 10.1038/nbt.1862.

59.Li Z, et al. Small RNA-mediated regulation of iPS cell generation. EMBO J. 2011;30(5):823-34. doi: 10.1038/emboj.2011.2.

60.Hashemizadeh, M.R, et al.(2015) “ Regulation of gene expression in neural stem cell Differentiation and self-Renewal” Shefaye Khatam 3(4)87-98.

\footnotetext{
How to Cite This Article:

Nezakat A.H, Sahraei N, Ahmadifar M. Regulation of gene expression in tissue engineering, differentiation and bone regeneration of ossifying stem cells Mod Med Lab J. 2020; 3(1) : $35-45$
} 